\title{
Bipolar Radiofrequency Ablation of Spinal Tumors: The Effect of the Posterior Vertebral Cortex Defect on Temperature Distribution in the Spinal Canal
}

W e read with interest the article in the June 2017 American Journal of Neuroradiology by Wallace et al entitled, "Percutaneous Spinal Ablation in a Sheep Model: Protective Capacity of an Intact Cortex, Correlation of Ablation Parameters with Ablation Zone Size, and Correlation of Postablation MRI and Pathologic Findings." " The researchers postulated that an intact cortex appears to protect against radiofrequency ablation-induced spinal cord injury, but not against non-impedance-based modalities. This conclusion is an important consideration in the treatment of spinal metastases with bipolar radiofrequency ablation (RFA).

In agreement with the accompanying commentary by Gemmete, ${ }^{2}$ we believe that more animal research with bipolar RFA systems is needed, in contrast to monopolar RFA. The main limitation of the study, as Wallace et $\mathrm{al}^{1}$ stated, is that the research was performed with normal bone, which is unlike the typical clinical situation. To strengthen the aforementioned conclusion and solve the limitation of the study, we present our preliminarily results as supportive data.

Tumors are known to affect the posterior vertebral cortex (PVC). ${ }^{3}$ An insulating effect of the PVC during monopolar RFA has been reported. ${ }^{4}$ Others have postulated that RFA should only be performed on patients with an intact PVC and not too far advanced osteolysis. ${ }^{5}$ No research regarding the effect of a PVC defect on temperature distribution during bipolar RFA in the spinal canal was found during our literature review. Thus, we performed our ex vivo research.

A preliminarily evaluation of the temperature distribution change during bipolar RFA in the spinal canal in porcine lumbar vertebrae was performed. As shown in Fig 1, lumbar vertebrae from 10 pigs were collected and randomly divided into 2 groups (4 lumbar vertebrae per group). Group 1 was the intact cortex group; and group 2 , the cortex defect group. The PVC defect was achieved by removal of the cortex with a rongeur. We used a radiofrequency generator connected to an expandable electrode catheter (1500X; AngioDynamics, Latham, New York) for the ablation. An infrared thermometer system (CTlaser LT; Optris, Berlin, Germany) was used to monitor the temperature. The highest temperature during RFA was recorded. RFA was performed on each sample for 15 minutes at the $75-\mathrm{W}$ setting and $95^{\circ} \mathrm{C}$. The temperature $\left(37.43^{\circ} \mathrm{C} \pm 4.43^{\circ} \mathrm{C}\right)$ in the intact cortex group was noted. A significant increase $\left(49.44^{\circ} \mathrm{C} \pm\right.$

http://dx.doi.org/10.3174/ajnr.A5393
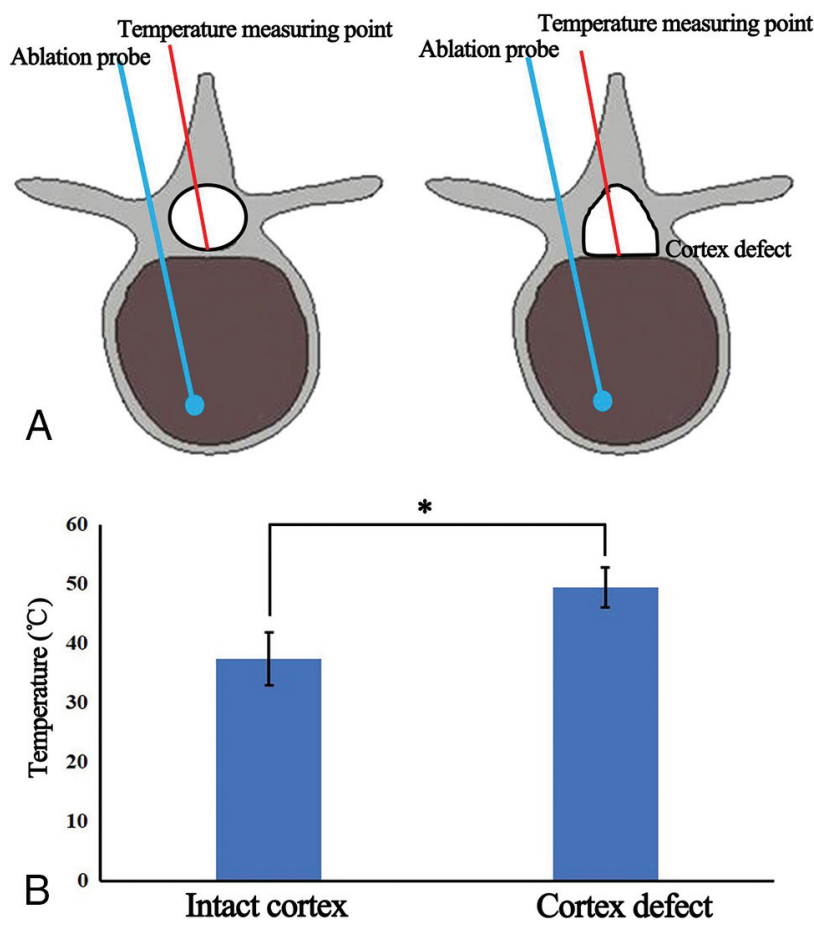

FIG 1. The effect of the posterior vertebral cortex defect on temperature distribution in the spinal canal during bipolar radiofrequency ablation.

$\left.3.34^{\circ} \mathrm{C}\right)$ was seen in the cortex defect group $(P<.01)$. Our data suggest that an intact PVC provides thermal isolation during bipolar RFA. For the cases with altered PVC, bipolar RFA is still a potentially safe therapy.

We offer these preliminary data suggesting that an intact PVC can potentially protect against RFA-induced spinal cord injury. We show changes in the temperature distribution within the spinal canal of the samples with PVC defects during bipolar RFA.

\section{REFERENCES}

1. Wallace AN, Hillen TJ, Friedman MV, et al. Percutaneous spinal ablation in a sheep model: protective capacity of an intact cortex, correlation of ablation parameters with ablation zone size, and correlation of postablation MRI and pathologic findings. AJNR Am J Neuroradiol 2017;38:1653-59 CrossRef Medline 
2. Gemmete JJ. Is an intact posterior vertebral body cortex protective for percutaneous ablation? AJNR Am J Neuroradiol 2017;38:1660-61 CrossRef Medline

3. Alkalay RN. Effect of the metastatic defect on the structural response and failure process of human vertebrae: an experimental study. Clin Biomech (Bristol, Avon) 2015;30:121-28 CrossRef Medline

4. Dupuy DE, Hong R, Oliver B, et al. Radiofrequency ablation of spinal tumors: temperature distribution in the spinal canal. $A J R A m J$ Roentgenol 2000;175:1263-66 CrossRef Medline

5. Bornemann R, Grötz SF, Pennekamp PH, et al. Radiofrequency ablation: temperature distribution in adjacent tissues. Z Orthop Unfall 2016;154:294-98 CrossRef Medline

Department of Bone and Soft Tissue Tumors Tianjin Medical University Cancer Institute and Hospital
National Clinical Research Center for Cancer Key Laboratory of Cancer Prevention and Therapy Tianjin's Clinical Research Center for Cancer Tianjin, China (D) P. Douglas Tianjin Medical University Tianjin, China (D) Y. Dai

Institute of Robotics and Automatic Information System Tianjin Key Laboratory of Intelligent Robotics College of Computer and Control Engineering, Nankai University Tianjin, China (1) G. Wang Department of Bone and Soft Tissue Tumors Tianjin Medical University Cancer Institute and Hospital National Clinical Research Center for Cancer Key Laboratory of Cancer Prevention and Therapy Tianjin's Clinical Research Center for Cancer Tianjin, China 